\title{
COMENTARIO DEL INFORME DEL GRUPO ESPECIAL DE LA OMC EN EL ASUNTO REPÚBLICA DOMINICANA - MEDIDAS DE SALVAGUARDIA SOBRE LAS IMPORTACIONES DE SACOS DE POLIPROPILENO Y TEJIDO TUBULAR (INFORME DE 31 DE ENERO DE 2012)*
}

\section{CRISTIÁN DELPIANO LIRA**}

\section{INTRODUCCIÓN}

Las normas de la Organización Mundial de Comercio permiten a sus Estados miembros adoptar medidas de defensa comercial (medidas Antidumping, derechos compensatorios y medidas de salvaguardia), cuando se cumplen determinados requisitos de procedimiento y de aplicación de la medida, cada uno detallado en sus normas.

En el caso de las medidas de salvaguardia, dichas normas se encuentran en el artículo XIX del Acuerdo General sobre Aranceles Aduaneros y Comercio (GATT, por sus siglas en inglés), y en el Acuerdo sobre Salvaguardias de la OMC (en adelante "AS") resultante de las negociaciones de la Ronda Uruguay de la década de los 90.

Dentro de este marco, el objetivo del presente comentario es analizar dos aspectos relevantes de las medidas de salvaguardia analizadas en el informe de un Grupo Especial creado dentro del contexto del Mecanismo de Solución de Diferencias de la OMC, en el caso República Dominicana - Medidas de Salvaguardia sobre las Importaciones de Sacos de Polipropileno y Tejido Tubular (Informe de 31 de enero de 2012).

El primer aspecto dice relación con el vínculo entre el denominado "principio de paralelismo" que debe existir entre la investigación y la aplicación de una medida de salvaguardia, con la exclusión de medidas de salvaguardia a países en desarrollo fundado en la norma del artículo 9.1 del AS.

El segundo aspecto consiste en el alcance de la obligación prevista en el artículo 9.1 del AS, que exige la exclusión de una medida de salvaguardia de los Estados miembros en desarrollo de la OMC, cuando se cumplen los requisitos previstos en dicha norma. En otras palabras, se trata de

El comentario que se presenta es parte de la ejecución del Proyecto Fondecyt de iniciación No 11130657 , del Ministerio de Educación de Chile.

** Doctor en Derecho por la Universidad de Salamanca (España). Profesor de Derecho Internacional Público de la Universidad Católica del Norte, Sede Coquimbo (Chile). Correo electrónico: cdelpiano@ucn.cl 
determinar el alcance de la obligación del Estado de excluir de la investigación previa a los productos de aquellos países que vayan a ser eximidos de la medida sobre la base del denominado "trato especial y diferenciado a los países en vías de desarrollo" previsto en el artículo 9.1 del Acuerdo sobre Salvaguardias.

En este sentido, y como explicación previa, la aplicación de una medida de salvaguardia requiere el desarrollo de una investigación por parte de las autoridades competentes del Estado miembro ${ }^{1}$, y con arreglo a un procedimiento previamente establecido y hecho público ${ }^{2}$. Dentro de este marco, el estudio debe comprender el impacto de la importación del producto de referencia a través de la evaluación del ritmo y la cuantía del aumento de las importaciones, la parte del mercado interno absorbida por las importaciones en aumento, entre otros factores ${ }^{3}$. Si de esta investigación, el Estado miembro considera que se cumplen los requisitos previstos en el artículo XIX del GATT, y del artículo 2.1 del AS , puede adoptar la medida, notificando de esta circunstancia al Comité de Salvaguardias de la OMC. Estas medidas pueden ser provisionales y/o definitivas, teniendo, en ambos casos, determinados plazos expresamente previstos en el AS.

El enfoque de este comentario se centrará en el contenido del denominado principio o doctrina del paralelismo, que ha sido desarrollada por el Órgano de Apelación de la OMC en diversos casos ${ }^{5}$, y los límites definidos para dicho principio en el informe objeto del presente comentario.

En este sentido, cabe señalar que se trató del primer caso en el que el principio de paralelismo es analizado desde una perspectiva diversa a la de la relación entre socios de un acuerdo de libre comercio (o de una unión

1 En el caso de Chile, de la Comisión de Distorsión de Precios establecido en la Ley $\mathrm{N}^{\circ}$ 18.525 .

2 Artículo 3.1 del AS.

3 Artículo 4.2 a) del AS

4 El artículo XIX del GATT, conjuntamente con el artículo 2.2 del AS, establece como requisitos: 1) la constatación de una evolución imprevista de las circunstancias, 2) que por efecto de las obligaciones contraídas por el Estado miembro de acuerdo a las normas del sistema GATT/OMC, produzcan 3) un aumento de las importaciones en tal cantidad o condiciones que, 4) causen o amenacen causar un daño grave a los productores nacionales de productos similares o directamente competidores

5 En este sentido, pueden verse los casos Argentina - Medidas de Salvaguardia Impuestas a las Importaciones de Calzado (WT/DS121/AB/R), Informe del Órgano de Apelación de 14 de diciembre de 1999; Estados Unidos - Medidas de Salvaguardia Definitivas Impuestas a las Importaciones de Gluten de Trigo Procedentes de las Comunidades Europeas (WT/DS166/AB/R), Informe del Órgano de Apelación de 22 de diciembre de 2000; Estados Unidos - Medidas de Salvaguardia Definitiva contra las Importaciones de Tubos al Carbono Soldados de Sección Circular Procedentes de Corea (WT/DS202/AB/R), Informe del Órgano de Apelación de 15 de febrero de 2002; y Estados Unidos - Medidas de Salvaguardia Definitivas sobre las Importaciones de Determinados Productos de Acero (WT/DS248/AB/R - WT/DS249/AB/R - WT/DS251/AB/R - WT/DS252/AB/R - WT/DS253/AB/R - WT/DS254/AB/R - WT/ DS258/AB/R - WT/DS259/AB/R), Informe del Órgano de Apelación de 10 de noviembre de 2003. 
aduanera) frente a una medida de salvaguardia. En efecto, en el presente informe, el principio de paralelismo es analizado desde la perspectiva del principio de trato especial y diferenciado previsto en el artículo 9.1 del AS.

\section{1) LOS HECHOS Y LA DISCUSIÓN JURÍDICA}

Durante el año 2010, la República Dominicana notificó a la Organización Mundial de Comercio (en adelante "OMC") la aplicación de medidas de salvaguardias provisionales y definitivas sobre las importaciones de tejido tubular y sacos de polipropileno, excluyendo de dicha aplicación a las importaciones originarias de Colombia, Indonesia, México y Panamá, países en desarrollo cuyas importaciones representaban el 1,21\% del total de las importaciones investigadas. En efecto, dicha exclusión tuvo como fundamento la norma del artículo 9.1 del AS. Dicha norma establece que:

"[n]o se aplicarán medidas de salvaguardia contra un producto originario de un país en desarrollo Miembro cuando la parte que corresponda a éste en las importaciones realizadas por el Miembro importador del producto considerado no exceda del 3 por ciento, a condición de que los países en desarrollo Miembros con una participación en las importaciones menor del 3 por ciento no representen en conjunto más del 9 por ciento de las importaciones totales del producto en cuestión”.

De esta forma, el artículo 9.1 constituye un elemento del denominado "trato especial y diferenciado" a los países en desarrollo miembros de la $\mathrm{OMC}$, en tanto permite hacer una distinción respecto de los productos provenientes de dichos Estados cuando no superan los umbrales definidos en dicha norma, como una excepción a la disposición del artículo $2.2 \mathrm{del} \mathrm{AS^{6 }}$.

Conforme a las normas expresamente previstas en el Entendimiento Relativo a las Normas y Procedimientos por los que se Rige la Solución de Diferencias de la OMC (en adelante "el Entendimiento"), esta medida fue impugnada por Costa Rica, Guatemala, Honduras y El Salvador, todos ellos de manera separada, estableciéndose un Grupo Especial con el mandato estándar establecido en el artículo 7 del mismo Entendimiento ${ }^{7}$.

6 El artículo 2.2 establece que "[1] as medidas de salvaguardia se aplicarán al producto importado independientemente de la fuente de donde proceda".

7 El mandato para este caso fue el siguiente: "Examinar, a la luz de las disposiciones pertinentes de los acuerdos abarcados invocados por las partes en la diferencia, el asunto sometido al OSD por Costa Rica en el documento WT/DS415/7, por El Salvador en el documento WT/DS418/7, por Guatemala en el documento WT/DS416/7 y por Honduras en el documento WT/DS417/7, y formular conclusiones que ayuden al [Órgano de Solución de Diferencias] a hacer las recomendaciones o dictar las resoluciones previstas en dichos acuerdos" (Párrafo 1.4 del Informe). 
El informe contiene diversas discusiones jurídicas relativas al alcance de los requisitos y condiciones de aplicación de medidas de salvaguardia dentro del marco de las normas $\mathrm{OMC}^{8}$. Sin embargo, para los efectos del presente comentario, nos centraremos en la discusión relativa al alcance de la aplicación del principio de paralelismo, y la consecuente exclusión de las medidas de salvaguardia a determinadas importaciones que sí fueron incluidas en la investigación previa a la adopción de la medida.

Dentro del marco de los requisitos de las medidas de salvaguardia, el artículo XIX del Acuerdo General sobre Aranceles Aduaneros y Comercio (GATT) y el artículo 2.1 del AS, las medidas de salvaguardia solo pueden ser impuestas de manera temporal, como consecuencia de la evolución imprevista de las circunstancias y por efectos de las obligaciones contraídas por el Estado de conformidad con las normas del GATT, en aquellos casos en que se produzca un aumento de las importaciones en cantidad tal o en condiciones tales que causen o que amenacen causar un daño grave a los productores nacionales de productos similares o directamente competidores en el territorio del Estado en que se impone la salvaguardia?.

Además, en aquellos casos en que se han excluido socios comerciales de medidas de salvaguardia, el Órgano de Apelación ha exigido el cumplimiento del denominado "principio de paralelismo", que implica que debe existir una identidad entre las importaciones consideradas para efectos de la etapa de investigación de salvaguardias y los productos a los que se aplica la medida (en términos del artículo 2.2 de dicho acuerdo) ${ }^{10}$. En consecuencia, exige una concordancia entre los productos investigados, y frente a los cuales se aplica efectivamente la medida.

El origen de esta doctrina se encuentra en el informe del Órgano de Apelación relativo al asunto Argentina-Calzados ${ }^{11}$, en el cual Argentina

8 Las restantes discusiones se refieren a: 1) la compatibilidad de la determinación de la rama de producción nacional con las normas del AS; 2) la razonabilidad y adecuación de la determinación de la evolución imprevista de las circunstancias y del efecto de las obligaciones del acuerdo GATT de 1994; 3) la compatibilidad de la determinación del incremento de las importaciones con ciertas normas del AS; 4) la compatibilidad de la determinación relativa al daño grave a la rama de producción nacional (y de circunstancias críticas en el caso de la aplicación de medidas de salvaguardia provisional) con las normas del AS; 5) la compatibilidad de la determinación de la relación de causalidad entre el incremento de las importaciones y el daño grave a la rama de producción nacional con ciertas normas del AS; y, 6) cuestiones relativas a la notificación de la medida (Véase en este sentido el párrafo 3.1 del Informe). Además, se plantearon otras cuestiones preliminares.

9 En estos puntos, el Grupo Especial no hizo mayores variaciones respecto de los criterios que previamente había desarrollado el Órgano de Apelación en estos requisitos. A mayor abundamiento, el Grupo Especial señaló que cuando los casos son similares, resulta esperable que los criterios que ha seguido el Órgano de Apelación en casos anteriores sean adoptados cuando las circunstancias sean similares (Párrafo 7.129).

10 Párrafo 7.367.

11 Argentina - Medidas de Salvaguardia Impuestas a las Importaciones de Calzado (WT/DS121/ $\mathrm{AB} / \mathrm{R})$, Informe del Órgano de Apelación de 14 de diciembre de 1999. 
realizó todo el proceso de investigación incluyendo las importaciones provenientes de los restantes Estados miembros del MERCOSUR. Sin embargo, al momento de aplicar la medida, las importaciones del MERCOSUR fueron excluidas. Las Comunidades Europeas sostuvieron que entre la investigación y la aplicación de medidas de salvaguardias debe existir una relación de coherencia. A mayor abundamiento, no discutieron la exclusión de los países del MERCOSUR, sino que "esa exclusión hubiera debido necesariamente entrañar la exclusión de las importaciones del MERCOSUR de los análisis relativos al 'aumento de las importaciones', al 'daño grave' y la 'causalidad', como establece el párrafo 1 del artículo 2 del Acuerdo sobre Salvaguardias" 12 .

El Órgano de Apelación, por su parte, señaló que Argentina no podía justificar la aplicación de sus medidas de salvaguardia solo a las fuentes de suministro de terceros países que no son miembros del MERCOSUR basándose en una investigación que constató la existencia o amenaza de daño grave causado por importaciones procedentes de todas las fuentes, con inclusión de las importaciones procedentes de otros Estados miembros del MERCOSUR ${ }^{13}$.

Cabe señalar que en los casos posteriores en que se ha invocado y desarrollado el principio de paralelismo, el fundamento ha sido la exclusión de socios comerciales en acuerdos de libre comercio, especialmente concluidos con Estados Unidos. Este caso, sin embargo, planteaba una cuestión adicional, consistente en la aplicación del principio de paralelismo ante la exclusión de otros Estados miembros bajo un argumento diverso al de que se trate o no de socios comerciales. En efecto, este caso sugería la pregunta de si acaso era necesario cumplir con el principio de paralelismo cuando la exclusión de otros Estados miembros se realiza sobre la base de la aplicación del principio de trato especial y diferenciado contenido en el artículo 9.1 del AS.

\section{2) El ANÁlisis DEL GRUPo EsPeCiAL}

Según se señaló en el apartado anterior, la cuestión a resolver por parte del Grupo Especial consistía en el alcance del principio de paralelismo en relación con el principio de trato especial y diferenciado contenido

12 En otras palabras, las CCEE no cuestionan el derecho que tiene un miembro de una unión aduanera de excluir a otro miembro de esa unión aduanera del ámbito de una medida de salvaguardia. Lo que objeta es utilizar las importaciones de esa unión aduanera en el análisis del aumento de las importaciones cuando no existe posibilidad de incluir esas importaciones en el ámbito de la medida de salvaguardia (Argentina-Calzado (WT/DS121/R), Informe del Grupo Especial, párrafos 5.67 y 5.68).

13 Argentina - Medidas de Salvaguardia Impuestas a las Importaciones de Calzado (WT/DS121/ AB/R), Informe del Órgano de Apelación de 14 de diciembre de 1999, párrafo 114. 
en el artículo 9.1 del $\mathrm{AS}^{14}$, cuestión específica sobre la cual no se había planteado controversia alguna con anterioridad. En efecto, de acuerdo a lo señalado por los reclamantes, la República Dominicana había considerado las importaciones provenientes de Colombia, Indonesia, México y Panamá del análisis del incremento de las importaciones, daño grave y causalidad. Sin embargo, sobre la base del artículo 9.1 del AS, excluyó dichas importaciones de la medida provisional y definitiva, sin realizar un nuevo análisis de incremento de las importaciones, daño grave y causalidad excluyendo las importaciones de Colombia, Indonesia, México y Panamá. Además, se alegaba que, en los mismos términos, debían excluirse de la medida las importaciones provenientes de Tailandia, en tanto Estado en desarrollo que habría cumplido con las condiciones prescritas en el artículo 9.1 del AS.

Así, el argumento principal de los reclamantes consistía en que la aplicación del artículo 9.1 del AS no exime del cumplimiento del principio de paralelismo, debido a que es una excepción a la norma de los artículos $2.1^{15}$ y $2.2^{16}$ del AS ${ }^{17}$. En efecto, mientras el artículo 2.1 del AS establece las condiciones de aplicación de la medida de salvaguardia ${ }^{18}$, el artículo 2.2 exige que la aplicación de una medida de salvaguardia se realice de forma no discriminatoria, o dicho de otra manera, bajo el principio Nación Más Favorecida ${ }^{19}$. En el caso comentado, la exclusión de los productos originarios de Colombia, Indonesia, México y Panamá supone que las ventajas concedidas a los mismos no han sido otorgadas en los mismos términos a los restantes Estados miembros de la OMC. En consecuencia, surge la pregunta de si en la determinación del cumplimiento de las condiciones de los productos de países en desarrollo para ser excluidos de la medida de salvaguardia, se deben seguir los pasos que ha sostenido el Órgano de Apelación en la investigación que la autoridad realiza previa

Véase supra.

El artículo 2.1 del AS establece que "[u]n Miembro solo podrá aplicar una medida de salvaguardia a un producto si dicho Miembro ha determinado, con arreglo a las disposiciones enunciadas infra, que las importaciones de ese producto en su territorio han aumentado en tal cantidad, en términos absolutos o en relación con la producción nacional, y se realizan en condiciones tales que causan o amenazan causar un daño grave a la rama de producción nacional que produce productos similares o directamente competidores" (nota al pie omitida). Véase supra nota 6.

Párrafo 7.357.

Sin perjuicio de las condiciones establecidas en el artículo XIX del GATT.

El principio Nación Más Favorecida, de acuerdo al artículo I del GATT, supone que toda ventaja, favor, privilegio o inmunidad concedido por un Estado miembro a un producto originario de otro país o destinado a él, debe ser concedido inmediata e incondicionalmente a todo producto similar originario de los territorios de todos los demás Estados miembros o a ellos destinado. 
a la adopción de la medida de salvaguardia, esto es, si se debe cumplir con el requisito de paralelismo ${ }^{20}$.

Por su parte, y ante la inclusión de Tailandia en la medida de salvaguardia impuesta por República Dominicana, el Grupo Especial identificó dos cuestiones distintas a resolver: 1) si la República Dominicana había cumplido el requisito de paralelismo; y, 2) si había un incumplimiento de la disposición del artículo 9.1 del AS al no excluirse las importaciones provenientes de Tailandia.

Respecto de la primera cuestión, comenzó reafirmando el principio del paralelismo tal como ya lo había hecho el Órgano de Apelación, señalando que el mismo se desprende del lenguaje paralelo utilizado en los artículos 2.1 y 2.2 del AS, y que alcanza la simetría que debe existir entre los artículos 2.1 y 4.2 del $\mathrm{AS}^{21}$.

Sin embargo, tanto los artículos 2.2 como 9,1 del AS se refieren únicamente a la aplicación de medidas, y no hacen referencia a la etapa de investigación. Por lo tanto, ambos "establecen una obligación de aplicar las medidas a los productos de todos los orígenes, excepto de aquellos orígenes que se ubiquen en las condiciones previstas en el artículo 9.1"22. A mayor abundamiento, el Grupo Especial señaló que "el artículo 9.1 del Acuerdo sobre Salvaguardias establece la obligación de excluir de la aplicación de la medida de salvaguardia una porción de las importaciones [...] aun cuando las mismas hayan sido consideradas en el análisis sustantivo en el curso de la investigación" 23 , y por tanto, no se trata de una facultad discrecional del Estado.

Respecto de la segunda cuestión, esto es, el contenido de la obligación prevista en el artículo 9.1 del AS, el Grupo Especial dio un paso más en la interpretación de esta norma, que ya había sido analizada en el asunto Estados Unidos-Tubos ${ }^{24}$. En efecto, el Grupo Especial consideró que los Estados miembros de la OMC "que apliquen medidas de salva-

20 Esto es, si previo a aplicar una medida de salvaguardia, el proceso de investigación debe 1) incorporar el total de las importaciones para el cálculo del incremento de las mismas, el daño grave y la relación de causalidad, para luego 2) realizar un nuevo análisis del incremento de las importaciones, dańo grave y causalidad, excluyendo las importaciones provenientes de los Estados en desarrollo que vayan a ser eximidos de la medida de salvaguardia.

21 Párrafo 7.367, véase en este sentido los asuntos Estados Unidos-Medidas de Salvaguardia Definitivas Impuestas a las Importaciones de Gluten de Trigo Procedentes de las Comunidades Europeas (WT/DS166/AB/R), Informe del Órgano de Apelación de 22 de diciembre de 2000 y Estados Unidos-Medidas de Salvaguardia Definitivas sobre las Importaciones de Determinados Productos de Acero (WT/DS248/AB/R-WT/DS249/AB/R-WT/DS251/AB/R-WT/DS252/ AB/R-WT/DS253/AB/R-WT/DS254/AB/R-WT/DS258/AB/R-WT/DS259/AB/R), Informe del Órgano de Apelación de 10 de noviembre de 2003.

Párrafo 7.375 .

Párrafo 7.381 (Cursiva añadida).

Estados Unidos-Medidas de Salvaguardia Definitiva contra las Importaciones de Tubos al Carbono Soldados de Sección Circular Procedentes de Corea (WT/DS202/AB/R), Informe del Órgano de Apelación de 15 de febrero de 2002. 
guardia tienen la obligación de adoptar todas las medidas razonables a su disposición para excluir a todos los países en desarrollo que se encuentren en las condiciones del artículo 9.1 del Acuerdo sobre Salvaguardias"25.

El artículo 9.1, sin embargo, no establece la forma en que haya de cumplirse esta obligación, por lo que existe cierta flexibilidad en la materia $^{26}$. Sin embargo, el Grupo Especial consideró que con independencia de la forma en que haya de efectuarse la evaluación, "es necesario que el Miembro en cuestión demuestre que realizó los esfuerzos a su alcance para excluir a todos los Miembros que se ubicaban en el supuesto del artículo 9.1 del [AS]"27, con lo que sitúa la carga de la prueba en el Estado que impone la medida de salvaguardia el cumplimiento de esta disposición, no siendo exigible al Estado en desarrollo miembro acreditar el cumplimiento de los requisitos para ser excluido de la medida.

\section{COMENTARIOS FINALES}

El informe objeto del presente comentario tiene 3 aspectos relevantes que deben ser apreciados en un contexto de una incompleta determinación de los aspectos vinculados a la adopción de medidas de salvaguardia adoptada por un Estado miembro de la OMC.

El primero de ellos, es la exclusión de la idea de que el principio de paralelismo pudiera tener un alcance general dentro del marco de las normas del artículo XIX del GATT y del AS. En este sentido, el sistema de solución de diferencias de la OMC mantiene la obligación de cumplir con el requisito de paralelismo solo dentro del contexto de la exclusión de socios comerciales, y no fuera de él.

El segundo aspecto, es la consideración especial hacia los países en desarrollo dentro del marco del trato especial y diferenciado previsto en el artículo 9.1 del AS. En este sentido, se destaca el derecho que tiene un Estado en desarrollo incluido dentro de la medida de salvaguardia para generar una disputa ante el Mecanismo de Solución de Diferencias por su falta de exclusión. La carga de la prueba, en este caso, le corresponde al Estado que adopta la medida, quien debe acreditar que realizó todos los esfuerzos necesarios para excluir a los Estados en Desarrollo. Descarta que sea el Estado en desarrollo quien deba acreditar que se encuentra dentro de los supuestos del artículo 9.1 para ser excluido. Así, obliga al Estado que impone la medida a realizar la investigación más completa posible en

Párrafo 7.393 (Cursiva en el original).

Párrafo 7.396.

Párrafo 7.396. 
orden a determinar los factores que permiten incluir a Estados en desarrollo dentro de la medida de salvaguardia.

Por último -y como tercer aspecto-, queda por determinar si existen otras consideraciones fuera de la disposición del artículo 9.1 del AS que permitan excluir Estados miembros de la OMC de medidas de salvaguardia. En este sentido, si bien estas medidas deben imponerse al producto importado con independencia de la fuente de procedencia, no está claro si el requisito de paralelismo puede servir como un fundamento en sí mismo para excluir otros Estados miembros de la OMC de la medida de salvaguardia, como es el caso del cumplimiento de ciertas normas de acuerdos comerciales que permiten (o que en algunos casos exigen) esta exclusión.

Esta cuestión no fue abordada en este caso por el Grupo Especial, a pesar de la existencia de acuerdos comerciales entre República Dominicana y los Estados excluidos. Sin embargo, ninguno de los reclamantes puso estos argumentos en el debate, centrando la cuestión en el trato especial y diferenciado a los países en desarrollo miembros de la OMC dentro de las normas del AS. 